\title{
Pengaruh Profilaksis Trombosis Vena Dalam dengan Heparin Subkutan dan Intravena terhadap aPTT dan Jumlah Trombosit pada Pasien Kritis di ICU RSUP Dr. Kariadi Semarang
}

\author{
Satrio Adi Wicaksono*, Jati Listijanto P*, Ery Leksana* \\ *Bagian Anestesiologi dan Terapi Intensif FK Undip/ RSUP Dr. Kariadi, Semarang
}

\section{ABSTRACT}

Background: Heparin has been used as therapy and as primary prophylaxis of Deep Vein Thrombosis (DVT), although the safety of heparin, especially in critically ill patients who are at high risk of bleeding is still a subject of debate. There is no comparative study that clearly show the effectivity and safetty of subcuteneous heparin as DVT prophylaxis.

Objective: To investigates the difference between the effect of subcutaneous heparin compared to intravenous heparin as DVT prophylaxis to the aPTT and platelet counts in critically ill patients in the intensive care unit (ICU) Dr. Kariadi Hospital Semarang.

Method: Clinical trials were conducted to 30 patients for 3 days by administering subcutaneous heparin 5000 IU bid for group $S K(n=15)$ and intravenous heparin 500 IU per hour for group IV $(n=15)$, several parameters of coagulation were compared $(D$ dimer, platelet counts, aPTT) in critically ill patients in the intensive care unit (ICU) Dr. Kariadi Hospital Semarang.

Result: After 3 days administration of DVT prophylaxis, significant decreased levels of D -dimer were obtained in both groups, SK groups 959.73(1127.539) $(p=0.05)$ and IV groups 1621.33(1041.654) ( $p=0.00)$, but no significant changes in aPTT values, $S K$ groups 0.032(0.5284) $(p=0.815)$ and IV groups 0.068(0.5718) $(p=0.652)$. Insignificant decrease were found in SK group platelet counts 413.3(51489.76) $(p=0.815)$, but in IV group this decrease were significant 30186.6(53488.86) $(p=0.046)$.

Conclusion: Subcutaneous heparin 5000 IU bid and intravenous heparin 500 IU per hour as a DVT prophylaxis can significantly reduce the level of D-dimer. No significant changes were observed in the value of aPTT in both groups but there is a significant decrease in platelet count in IV group.

Keywords: heparin, DVT, D-dimer, aPTT, platelet count

\section{ABSTRAK}

Latar belakang: Heparin telah digunakan sebagai terapi maupun sebagai profilaksis primer TVD, walaupun keamanan heparin khususnya pada pasien kritis yang memiliki risiko tinggi perdarahan masih merupakan subyek perdebatan. Belum ada studi prospektif komparatif yang tegas menunjukkan efektivitas dan keamanan pemberian heparin subkutan sebagai profilaksis TVD pada pasien kritis di ICU.

Tujuan: Untuk mengetahui perbedaan pengaruh pemberian heparin subkutan dibandingkan intravena sebagai profilaksis TVD terhadap nilai aPTT dan jumlah trombosit pada pasien kritis di ICU.

Metode: Uji klinik dilakukan pada 30 pasien selama 3 hari dengan pemberian heparin subkutan 5000 IU b.i.d sebagai kelompok SK $(n=15)$ dan heparin 500 IU/jam intravena sebagai kelompok IV $(n=15)$ kemudian dibandingkan beberapa parameter koagulasi $(D$ - 
dimer, aPTT dan trombosit) pada pasien kritis di ICU.

Hasil: Setelah 3 hari diberikan profilaksis TVD didapatkan hasil yang bermakna penurunan kadar D-dimer pada kedua kelompok, kelompok SK 959.73(1127.539) $(p=0.05)$ dan kelompok IV 1621.33(1041.654) $(p=0.00)$. Tetapi didapatkan hasil yang tidak bermakna pada perubahan nilai aPTT, kelompok SK 0.032(0.5284) $(p=0.815)$ dan kelompok IV 0.068(0.5718) ( $p=0.652)$. Perubahan jumlah trombosit didapatkan hasil tidak bermakna pada kelompok SK 413.3(51489.76) ( $p=0.815)$ sedangkan pada kelompok IV didapatkan perubahan yang bermakna dalam penurunan jumlah trombosit 30186.6(53488.86) $(p=0.046)$.

Simpulan: Pemberian heparin subkutan 5000 IU b.i.d dan heparin 500 IU/jam intravena sebagai profilaksis TVD secara bermakna dapat menurunkan kadar D-dimer. Tetapi didapatkan hasil yang tidak bermakna pada perubahan nilai aPTT dan perubahan yang bermakna pada kelompok heparin IV dalam penurunan jumlah trombosit.

Kata Kunci: Heparin, TVD, aPTT, jumlah trombosit.

\section{PENDAHULUAN}

Trombosis vena dalam (TVD) pada pasien kritis memerlukan perhatian khusus baik dari segi medis maupun ekonomi akibat besarnya biaya kesehatan yang ditimbulkan. ${ }^{1}$ Sekitar $10-33 \%$ dari keseluruhan pasien yang dirawat di rumah sakit menderita TVD (hospital acquired) dan lebih dari 10\% dari pasien tersebut adalah pasien kritis di ICU. ${ }^{1-8}$ TVD berulang terjadi pada sekitar 35\% pasien kritis dengan TVD, sekitar 23\% berkembang menjadi sindroma pasca trombosis ${ }^{3}$, yang sering menyebabkan komplikasi jangka panjang. TVD dapat berkembang menjadi tromboflebitis atau emboli paru yang akan meningkatkan morbiditas dan mortalitas. ${ }^{13-15}$

Pasien kritis berisiko terkena TVD akibat gangguan aliran darah vena (stasis) atau aliran darah yang lambat (low flow) karena imobilisasi dan inaktivitas, disfungsi endotel vaskular, hiperkoagulabilitas, serta pengaruh penyakit yang mendasarinya. Semua faktor tersebut berperan dalam pembentukan penggumpalan darah (clot) karena keseimbangan sistem koagulasi dan fibrinolisis terganggu. ${ }^{4,5,6}$ Di samping itu, pasien kritis sering disertai dengan Systemic Inflammatory Response Syndrome (SIRS) atau sepsis yang diperburuk dengan adanya Disseminated Intravascular Coagulation (DIC). Pasien kritis dengan DIC ini mengalami reaksi inflamasi dan ketidakseimbangan sistem koagulasi, berupa aktivasi koagulasi, penghambatan fibrinolisis dan konsumsi inhibitor koagulasi, yang menyebabkan hiperkoagulasi dan deposisi fibrin dalam pembuluh darah kecil.

Kondisi ini membutuhkan penatalaksanaan agresif terhadap penyakit yang mendasari dan penghambatan koagulasi yang efektif. Heparin telah digunakan sebagai terapi maupun profilaksis primer terhadap TVD pada kondisi biasa maupun pada kondisi kritis sesuai rekomendasi American College of Chest Physicians, 9,16-19 
walaupun keamanan heparin intravena khususnya pada pasien kritis yang memiliki risiko tinggi perdarahan masih menjadi perdebatan. ${ }^{19}$

\section{Low Molecular Weight Heparin} (LMWH) subkutan telah dinyatakan setara dalam efektivitas dan risiko perdarahannya dengan unfractionated heparin (UFH) intravena, serta dianggap memiliki beberapa kelebihan dibandingkan UFH intravena, antara lain lebih praktis dan tidak memerlukan pemantauan laboratorium rutin. ${ }^{17-24}$

Namun demikian, LMWH subkutan perlu dipertimbangkan bila diberikan pada pasien kritis yang seringkali sudah mengalami penurunan fungsi ginjal, karena memungkinkan terjadinya akumulasi LMWH dan efek perdarahan pada pasien kritis dengan penurunan fungsi ginjal tersebut. ${ }^{25-27}$

Pemberian UFH subkutan dapat dijadikan alternatif pencegahan TVD pada pasien kritis, yang mungkin lebih aman, praktis (tanpa pengawasan laboratorium rutin), dan murah dibandingkan UFH intravena dan LMWH subkutan pada pasien kritis. ${ }^{27}$

Beberapa penelitian menyebutkan bahwa UFH subkutan dan UFH intravena memiliki tingkat efektifitas dan keamanan yang sama sebagai profilaksis TVD. ${ }^{28}$ Pada penelitian lainnya menunjukkan bahwa UFH subkutan ternyata lebih baik dari UFH intravena dalam menurunkan ukuran trombus, ${ }^{29-32}$ sehingga UFH subkutan diharapkan dapat menjadi alternatif yang aman dan efektif dibandingkan UFH intravena. Namun, belum ada studi prospektif komparatif yang tegas menunjukkan efektivitas dan keamanan pemberian heparin subkutan sebagai profilaksis TVD pada pasien kritis di unit perawatan intensif (ICU). Oleh karena itu, diperlukan sebuah penelitian yang membandingkan pemberian profilaksis UFH subkutan dan UFH intravena sebagai pencegahan TVD dan pengaruhnya terhadap nilai aPTT dan jumlah trombosit.

\section{METODE}

Penelitian ini merupakan uji klinik eksperimental tahap II yang dilakukan secara acak tersamar ganda, dengan tujuan mencari perbedaan status koagulasi pada pasien kritis yang mendapatkan heparin subkutan (SK) dibandingkan dengan pasien yang mendapatkan heparin intravena (IV). Pengacakan dilakukan dengan permutasi random blok.

Sampel diambil dari pasien ICU/HCU RSUP Dr. Kariadi Semarang menggunakan "Consecutive Sampling" terdiri atas : 30 orang kelompok SK, 30 orang kelompok IV. Dengan kriteria inklusi usia 16-70 tahun, pasien kritis di ICU yang memiliki resiko TVD, dan setuju diikutkan dalam penelitian. Kriteria eksklusi pasien dengan kelainan fungsi hati dan menolak ikut dalam penelitian. Bila terjadi perdarahan medis akan dikeluarkan dari penelitian . 
Sampel diperiksa di laboratorium RSUP Dr. Kariadi Semarang. Hasil pemeriksaan laboratorium tersebut digunakan sebagai data dasar. Pasien yang memenuhi kriteria, diberikan heparin subkutan 5000 IU per 12 jam (kelompok SK) dan heparin intravena $500 \mathrm{IU} / \mathrm{jam}$ (kelompok IV).

Pemberian heparin subkutan dilakukan pada daerah lengan. Diberikan dengan spuit 1cc heparin 5000 IU selama 3 hari. Sedangkan pemberian heparin intravena $500 \mathrm{IU} / \mathrm{jam}$ diberikan secara intravena dengan Syring Pump (SP) dengan spuit $20 \mathrm{cc}$ konsentrasi $500 \mathrm{IU} /$ cc. Kemudian SP dijalankan 1 cc/jam selama 3 hari.

Dilakukan pemeriksaan kadar D-dimer, PTT dan trombosit pada hari ke-1, 2 dan 3. Hasil pemeriksaan dibandingkan dengan data dasar. Kemudian dilakukan analisis statistik.

Pemantauan berdasarkan tanda vital, yaitu tekanan darah, frekuensi nadi, frekuensi napas, suhu, saturasi oksigen dan adanya perdarahan medis. Bila terjadi perdarahan medis, pasien akan dikeluarkan dari penelitian.

\section{HASIL}

Didapatkan 33 subjek penelitian yang mendapat heparin profilaksis subkutan atau intravena dan masuk kriteria inklusi. Subjek setuju diikutsertakan dalam penelitian dan menandatangani informed consent. Selanjutnya subjek penelitian dikelompokkan secara acak menjadi kelompok SK sebanyak 17 orang dan kelompok IV sebanyak 16 orang.

Tiga orang subjek dikeluarkan dari penelitian karena mengalami perdarahan medis. Dua orang dari kelompok SK dan satu orang dari kelompok IV. Ketiga subjek tersebut tidak diikutsertakan dalam analisis tetapi profilnya akan dibahas lebih lanjut. Sehingga total sampel penelitian ini adalah sebanyak 15 orang kelompok SK dan 15 orang kelompok IV.

Pada Tabel 1 diperlihatkan data dasar seluruh subjek. Umur rerata grup SK 42.5(1.74) tahun, tidak berbeda bermakna dengan rerata umur grup IV yaitu 45.7(1.83) ( $\mathrm{p}=0.62)$. Kelompok SK terdiri dari 9 orang laki-laki dan 6 orang perempuan, secara statistik tidak berbeda bermakna dengan kelompok IV yaitu 4 orang laki-laki dan 11 orang perempuan $(p=0.06)$. Tidak dijumpai perbedaan bermakna untuk parameter umur, BMI, dan Skor APACHE II awal pada kedua kelompok sebelum perlakuan, demikian pula dengan hitung trombosit dan aPTT awal. Pada kedua kelompok, sebagian besar subjek adalah pasien pasca operasi bedah digestif. (Tabel 2).

Terdapat perbedaan bermakna antara kedua kelompok untuk parameter Ddimer awal, dimana pada kelompok SK lebih tinggi secara bermakna.

Perubahan parameter status koagulasi kelompok SK dan IV antara hari ke-1, hari ke-2 dan hari ke-3 ditunjukkan pada 
Tabel 3. Data perubahan parameter status koagulasi sebelum dan sesudah mendapat profilaksis diuji normalitasnya menggunakan uji Shapiro-Wilk dan didapatkan distribusi data yang normal untuk semua parameter $(p>0,05)$. Data yang didapat kemudian diuji perbedaan reratanya dengan uji $\mathrm{T}$-berpasangan.

Pada kelompok SK terjadi penurunan nilai D-dimer pada hari ke-2 [410.07 (807.303), $\quad \mathrm{p}=0,69]$ dan hari ke-3 profilaksis [959.73(1127.539), $\mathrm{p}=0,05]$. Pada kelompok IV terjadi penurunan nilai D-dimer pada hari ke-2 [1043.33 (807.303), $p=0,02]$ dan hari ke-3 [1621.33(1041.654), $\mathrm{p}=0,00]$.

Tidak terdapat perbedaan bermakna secara statistik antara pemberian heparin subkutan dan heparin intravena dalam menurunkan kadar D-Dimer $(p=0.07$ pada beda hari ke-1 dan 2, dan $\mathrm{p}=0.1$ pada beda hari ke-1 dan 3).

Nilai aPTT meningkat pada pemberian heparin SK, baik pada hari ke-2 [0.018 (0.3675), $\mathrm{p}=0.852]$ maupun hari ke-3 [0.032(0.5284), $\mathrm{p}=0.815]$, akan tetapi peningkatan tersebut tidak bermakna secara statistik. Sedangkan nilai aPTT lebih rendah pada pemberian heparin IV, baik pada hari ke-2 [0.047(0.4409), $\mathrm{p}=0.687]$ maupun hari ke-3 [0.068 (0.5718), $\quad \mathrm{p}=0.652]$, akan tetapi penurunan tersebut tidak bermakna secara statistik.

Tidak terdapat perbedaan bermakna secara statistik antara pemberian heparin subkutan dan heparin intravena dalam perbedaan aPPT $(\mathrm{p}=0.665$ pada hari ke1 dan 2 , dan $\mathrm{p}=0.621$ pada hari ke-1 dan 3). Hal ini ditunjukkan pada tabel 4.

Pada hari ke-2 pemberian heparin SK, terjadi penurunan nilai trombosit [2046.67(22532.385), p=0.730], akan tetapi pada hari ke-3 kemudian terjadi peningkatan $\quad$ 4413.33(51489.761), $\quad \mathrm{p}=$ 0.815]. Baik penurunan maupun kenaikan jumlah trombosit tersebut tidak bermakna secara statistik. Sedangkan pada pemberian heparin IV didapatkan penurunan jumlah trombosit terjadi baik pada hari ke-2 [54933(10671.1), p= 0.009] maupun ke-3 [70920(9414.941), $\mathrm{p}=0.008$ ]. Penurunan jumlah trombosit tersebut bermakna secara statistik pada hari ke-3.

Tidak terdapat perbedaan bermakna secara statistik antara pemberian heparin subkutan dan heparin intravena dalam penurunan jumlah trombosit $(p=0.102$ pada hari ke- 1 dan 2 , dan $\mathrm{p}=0.132$ pada hari ke-1 dan 3)

\section{PEMBAHASAN}

Terapi standar TVD adalah UFH intravena dan LMWH subkutan, selain trombolitik dan embolektomi. Chest Guidelines for Antithrombotic Therapy for Venous Thromboembolic Disease tahun 2008 merekomendasikan UFH 5 hari secara infus kontinyu, UFH subkutan atau LMWH subkutan, dan warfarin untuk terapi tromboemboli vena (TEV). ${ }^{17,18}$

Diagnosis TVD secara klinis terkadang sulit, karena $75 \%$ pasien yang diduga 
Tabel 1. Karakteristik Awal Subyek Penelitian

\begin{tabular}{llll}
\hline Parameter & SK & IV & $\mathrm{p}^{*}$ \\
\hline Jenis Kelamin(L:P) & $9: 6$ & $4: 11$ & 0.069 \\
Umur & $42.5 \pm 1.74$ & $45.7 \pm 1.83$ & 0.62 \\
BMI & $25.3 \pm 2.49$ & $24.05 \pm 3.13$ & 0.23 \\
Apache & $13.7 \pm 4.6$ & $14,5 \pm 7.67$ & 0.754 \\
Trombosit & $155353 \pm 80033.2$ & $230667 \pm 36661.2$ & 0.84 \\
PPT/K & $1.10 \pm 0.405$ & $1.28 \pm 0.412$ & 0.225 \\
D-Dimer & $4082 \pm 1238,5$ & $2990 \pm 1356,8$ & $0.029^{*}$ \\
\hline
\end{tabular}

Tabel 2. Jenis peny akit masing-masing kelomp ok

\begin{tabular}{lcccc}
\hline & \multicolumn{2}{c}{ Kelompok SK } & \multicolumn{2}{c}{ Kelompok IV } \\
\cline { 2 - 5 } \multicolumn{1}{c}{ Jenis Penyakit } & Jumlah & Persentase & Jumlah & Persentase \\
\hline Post Op B.Digestif & 8 & $53.3 \%$ & 7 & $46.7 \%$ \\
Post op Obstetri & 3 & $20.0 \%$ & 2 & $13.3 \%$ \\
Post op Ginekologi & 1 & $6.7 \%$ & 1 & $6.7 \%$ \\
Post op B. Orthopedi & 1 & $6.7 \%$ & 0 & $0.0 \%$ \\
Post op B. Vaskuler & 0 & $0.0 \%$ & 1 & $6.7 \%$ \\
Post op B. Urologi & 1 & $6.7 \%$ & 0 & $0.0 \%$ \\
Multiple trauma & 1 & $6.7 \%$ & 0 & $0.0 \%$ \\
Post op. B. Onkologi & 0 & $0.0 \%$ & 1 & $6.7 \%$ \\
Peny. Vaskuler & 0 & $0.0 \%$ & 1 & $6.7 \%$ \\
Sepsis sebab lain & 0 & $0.0 \%$ & 2 & $13.3 \%$ \\
\hline
\end{tabular}


TVD ternyata tidak menderita TVD. Diagnosis pasti TVD adalah venografi, dengan sensitifitas dan spesifisitas mencapai $100 \%$. Kelemahan venografi adalah bersifat invasif dan mempunyai efek samping flebitis serta trombosis, sehingga venografi tidak digunakan sebagai alat bantu pertama dalam mendiagnosis TVD. ${ }^{33}$

Pada penelitian ini digunakan heparin sebagai profilaksis TVD, dengan menilai efeknya terhadap kadar Ddimer, aPTT, dan jumlah trombosit sebagai parameter koagulasi.

\section{D-dimer}

Hasil dari aktivasi koagulasi yaitu pada pemecahan fibrinogen menjadi fibrin, molekul fibrin secara spontan beragregasi menjadi jaring fibrin dibantu oleh faktor XIII, menghasilkan gumpalan fibrin. Dengan adanya jaring fibrin, plasmin akan melepas fibrin degradation product (FDP) yang terikat silang D-Domain dengan unit terkecil adalah D-dimer. ${ }^{34,35}$

Deteksi adanya jaring fibrin dengan FDP dari D-dimer menunjukkan adanya reaksi fibrinolisis. Hal ini menunjukkan adanya hubungan antara uji D-dimer pada diagnosis tromboemboli. Kenaikan konsentrasi D-dimer menunjukkan keberadaan trombus, dan hal ini dapat ditemukan pada keadaan TVD, emboli paru dan DIC.

Pada penelitian ini didapatkan hasil perubahan kadar D-dimer setelah pemberian heparin subkutan dan intravena sebagai profilaksis TVD seperti digambarkan pada Tabel 3.

Pada kelompok SK terjadi penurunan nilai D-Dimer pada hari ke-2 $(\mathrm{p}=0,69)$ dan hari ke-3 $(\mathrm{p}=0,05)$, dimana penurunan tersebut bermakna secara statistik pada hari ke-3. Pada kelompok IV terjadi penurunan nilai D-dimer pada hari ke-2 $(p=0,02)$ dan hari ke-3 $(p=0,00)$, dimana penurunan tersebut bermakna secara statistik.

Tidak terdapat perbedaan bermakna secara statistik antara pemberian heparin subkutan dan heparin intravena dalam menurunkan kadar D-dimer $(p=0.07$ pada hari ke-1 dan 2 , dan $\mathrm{p}=0.1$ pada hari ke-1 dan 3).

Hal ini sesuai dengan penelitian sebelumnya yang menyatakan bahwa pemberian heparin subkutan dan intravena dapat digunakan sebagai profilaksis TVD. Doyle et al melaporkan bahwa pemberian heparin IV dan subkutan sama efektifnya dalam mencegah terjadinya emboli paru pada pasien dengan TVD, demikian pula dengan Kearon et al. Sementara Walker et al justru menyatakan bahwa pemberian UFH subkutan fixed-dose lebih efektif dari LMWH pada pasien TEV akut.

Dalam penelitian ini, pemberian heparin subkutan dalam mencegah trombosis secara statistik memiliki tingkat efektifitas yang sama dengan pemberian heparin intravena. 
Tabel 3. Perbedaan rerata selisih kadar D-Dimer selama 3 hari perlakuan

\begin{tabular}{ccccccc}
\hline Rerata Selisih & & \multicolumn{2}{c}{ Kelompok SK } & \multicolumn{2}{c}{ Kelompok IV } & \multirow{2}{*}{ P** $^{*}$} \\
\cline { 3 - 6 } & & mean \pm SD & $\mathrm{P}^{*}$ & mean \pm SD & P* & \\
\hline D-Dimer & H1 dan H2 & $410.07 \pm 807.303$ & 0,69 & $1043.33 \pm 807.303$ & 0,02 & 0.073 \\
& H1 dan H3 & $959.73 \pm 1127.539$ & 0.05 & $1621.33 \pm 1041.654$ & 0,00 & 0.106 \\
\hline
\end{tabular}

* bermakna bila $\mathrm{p}<0.05$

** antar kelompok, bermaknabila $\mathrm{p}<0.05$

Tabel 4. Perbedaan rerata selisih PTT/K selama 3 hari perlakuan

\begin{tabular}{lcccccc}
\hline Rerata Selisih & & \multicolumn{2}{c}{ Kelompok SK } & \multicolumn{2}{c}{ Kelompok IV } & \multirow{2}{*}{ P** $^{*}$} \\
\cline { 3 - 6 } & & mean \pm SD & P* & mean \pm SD & P* & \\
\hline PTT/K & H1 dan H2 & $0.018 \pm 0.3675$ & 0.852 & $0.047 \pm 0.4409$ & 0.687 & 0.665 \\
& H1 dan H3 & $0.032 \pm 0.5284$ & 0.815 & $0.068 \pm 0.5718$ & 0.652 & 0.621 \\
\hline
\end{tabular}

* bermakna bila $\mathrm{p}<0.05$

** antar kelompok, bermakna bila $\mathrm{p}<0.05$

Tabel 5. Perbedaan rerata jumlah trombosit selama 3 hari perlakuan

\begin{tabular}{|c|c|c|c|c|c|c|}
\hline & & \multicolumn{2}{|c|}{ Kelompok SK } & \multicolumn{2}{|c|}{ Kelompok IV } & \multirow[t]{2}{*}{$\mathrm{P}^{* * *}$} \\
\hline & & mean \pm SD & $\mathrm{P}^{*}$ & mean $\pm \mathrm{SD}$ & $\mathrm{P}^{*}$ & \\
\hline Rerata & $\mathrm{H} 1$ dan $\mathrm{H} 2$ & $2046.7 \pm 22532.3$ & 0.730 & $24600 \pm 46560.06$ & 0.060 & 0.102 \\
\hline Selisih & & 9 & & & & \\
\hline Trombosit & $\mathrm{H} 1$ dan $\mathrm{H} 3$ & $413.3 \pm 51489.76$ & 0.815 & $30186.6 \pm 53488.86$ & 0.046 & 0.132 \\
\hline
\end{tabular}

* bermakna bila $\mathrm{p}<0.05$

** antar kelompok, bermaknabila $\mathrm{p}<0.05$ 
Activated Partial Tromboplastin Time (aPTT)

Waktu yang diperlukan untuk membentuk suatu bekuan adalah activated Partial Tromboplastin Time (aPTT), dalam keadaan normal bervariasi dari 60-80 detik. aPTT menilai jalur koagulasi intrinsik dan jalur koagulasi bersama. Uji ini mengukur adanya faktor- faktor VIII, IX, XI, dan XII, yang semuanya harus ada dalam kadar memadai agar hasil uji normal. Faktor V dan X, protrombin dan fibrinogen juga harus ada. Faktor VII tidak diperlukan untuk aPTT karena uji ini melewatkan sistem ekstrinsik. ${ }^{36}$

Pada kadar heparin yang tinggi, defek fibrinogen kongenital, atau keadaan yang menyebabkan tingginya kadar produk penguraian fibrin (Fibrin Degradation Product), aPTT biasanya memanjang dan tidak mengukur aktivitas faktor XIII. Pada tingkat yang lebih praktis PTT digunakan untuk memantau pasien yang mendapatkan terapi heparin. ${ }^{36}$

Pada penelitian ini didapatkan nilai aPTT setelah pemberian heparin subkutan dan intravena sebagai profilaksis TVD seperti digambarkan pada Tabel 5.

Nilai aPTT meningkat pada pemberian heparin subkutan, baik pada hari ke-2 $(p=0.852)$ maupun hari ke-3 $(p=0.815)$, akan tetapi peningkatan tersebut tidak bermakna secara statistik. Sedangkan nilai aPTT menurun pada pemberian heparin intravena, baik pada hari ke-2 $(p=0.687)$ maupun hari ke-3 $(p=0.652)$, penurunan tersebut tidak bermakna secara statistik.

Tidak terdapat perbedaan bermakna secara statistik antara pemberian heparin subkutan dan heparin intravena dalam perbedaan aPTT $(\mathrm{p}=0.665$ pada hari ke- 1 dan 2 , dan $\mathrm{p}=0.621$ pada hari ke- 1 dan 3).

Hal ini tidak sesuai dengan teori yang menyatakan nilai aPTT akan memanjang 1,5-2 kali setelah pemberian terapi heparin, hal ini mungkin disebabkan oleh waktu pemberian yang hanya 3 hari dan penggunaan dosis profilaksis dalam penelitian ini.

\section{Trombosit}

Trombosit adalah fragmen tidak berinti dari sitoplasma megakariosit, dimana trombosit dapat menyumbat lubang kecil di pembuluh darah dan dapat membentuk suatu mekanisme hemostatik primer yang efektif. ${ }^{36,37}$

Trombositopenia dapat terjadi pada pasien yang mendapatkan heparin profilaksis maupun terapeutik. Sekitar $5 \%$ pasien yang mendapat heparin baik untuk profilaksis maupun terapi mengalami sindrom Heparin Induced Thrombocytopenia (HIT), yang menyebabkan heparin menjadi penyebab tersering trombositopenia akibat obat. ${ }^{36}$

Pada penelitian ini didapatkan hasil jumlah trombosit setelah pemberian Heparin subkutan (SK) dan Heparin 
intravena sebagai profilaksis TVD seperti digambarkan pada Tabel 6 .

Pada hari ke-2 pemberian heparin subkutan, terjadi penurunan jumlah trombosit $(p=0.730)$, akan tetapi pada hari ke-3 terjadi peningkatan $(\mathrm{p}=0.815)$. Baik penurunan maupun kenaikan jumlah trombosit tersebut tidak bermakna secara statistik. Sedangkan pada pemberian heparin intravena didapatkan penurunan jumlah trombosit baik pada hari ke-2 ( $\mathrm{p}=0.06)$ dan ke-3 $(p=0.046)$. Penurunan trombosit tersebut bermakna secara statistik pada hari ke-3.

Tidak terdapat perbedaan bermakna secara statistik antara pemberian heparin subkutan dan intravena dalam penurunan jumlah trombosit $(\mathrm{p}=0.102$ pada hari ke-1 dan 2 , dan $\mathrm{p}=0.132$ pada hari ke-1 dan 3).

Terdapat dua jenis HIT, yaitu jenis autoimun dan non-autoimun. Pada awal pemberian terapi heparin, jenis nonautoimun lebih sering terjadi.

Mekanisme terjadinya trombositopenia non-autoimun yang diinduksi heparin belum diketahui secara pasti, namun diduga bahwa hal tersebut terkait dengan sifat proagregasi heparin. Karena terjadi peningkatan agregasi trombosit, maka konsumsi trombosit oleh tubuh akan meningkat dan menyebabkan penurunan jumlah trombosit. Peningkatan agregasi trombosit oleh heparin bersifat sementara, oleh karena itu biasanya trombositopenia yang terjadi biasanya ringan dan hitung trombosit akan kembali normal.

Hal tersebut menjelaskan terjadinya peningkatan jumlah trombosit pada pemberian heparin subkutan pada hari ke -3, walaupun tidak bermakna secara statistik.

\section{SIMPULAN}

Pemberian heparin subkutan dan heparin intravena sebagai profilaksis TVD terbukti secara bermakna menurunkan kadar D-dimer.

Pemberian heparin subkutan dan intravena sebagai profilaksis TVD terbukti tidak bermakna dalam peningkatan aPTT.

Pemberian heparin subkutan sebagai profilaksis TVD terbukti tidak bermakna dalam menurunkan jumlah trombosit sedangkan pada pemberian heparin intravena terbukti bermakna dalam menurunkan jumlah trombosit .

\section{DAFTAR PUSTAKA}

1. Goldhaber SZ. Epidemiology of- pulmonary embolism. Semin Vasc Med 2001 ;1:139-146.

2. Stratton MA, Anderson FA, Bussey HI, et al. Preventionof-venous thromboembolism: Adherence to the 1995American College of Chest Physicians consensus guidelinesfor surgical patients. Arch Intern Med. 2000;160:334-340.

3. Kahn SR. Frequency and determinants of the postthromboticsyndrome after venous thromboembolism.CurtOpinPulm Med 2006;12:299-303. 
4. Cade JF.High risk of the critically ill for venous thromboembolism.Crit Care Med 1982;10:448-450.

5. Belch J J, Lowe GD, Ward AG, et al. Prevention of deep veinthrombosis in medical patients by low-dose heparin. ScottMedJ 1981;26:115-117.

6. Hirsch DR, Ingenito EP, Goldhaber SZ Prevalence of deepvenous thrombosis among patients in medical intensivecare.JAMA 1995;274:335-337.

7. Silverstein MD, Heir JA, Mohr DN,et at. Trends in the incidence of deepvein thrombosis and pulmonary embolism:A 25 year population-basedstudy. Arch Intern Med1998;158:585-593.

8. McGarry LJ, Thompson D. Retrospectivedatabase analysis of theprevention of venous thromboembolismwith low-molecularweightheparin in acutely ill medical inpatientsin community practice. ClinTher 2004;26:419-430.

9. Heit JA. Venous thromboembolism epidemiology: implications for prevention and management. SeminThrombHemost 2002, 28(Suppl 2):3-13.

10. White RH. The epidemiology of venous thromboembolism. Circulation 2003; 107 (Suppl):I4-I8.

11. Heit JA, Cohen AT, Anderson FJ.Estimated annual number of incident and recurrent, non-fatal venous thromboembolism (VTE) events in the US.Blood.2005; 106: 11.

12. Heit JA, Silverstein MD, Mohr DN, Petterson TM, O'Fallon WM, Melton III LJ. Risk factors for deep vein thrombosis and pulmonary embolism: a populationbased case-control study. Arch Intern Med 2000 (Mar 27);160(6):809-15.

13. O'Brien JA, Caro JJ. Direct medicalcost of managing deep vein thrombosisaccording to the occurrence ofcomplications.Pharmacoeconomics2002;2 0:603-615.

14. Anderson FA Jr, Wheeler HB,Goldberg RJ, et al.A population-basedperspective of the hospitalincidence and case-fatality ratesof deep vein thrombosis and
pulmonaryembolism.The WorcesterDVT Study.Arch Intern Med 1991;151:933-938.

15. Prandoni P, Lensing AW, CogoA, etal. The long-term clinical course ofacute deep venous thrombosis.AnnIntern Med 1996;125:1-7.

16. Geerts WH, Bergqvist D, Pineo GF, Heit JA, Samama CM, Lassen MR, Colwell CW. Prevention of venous thromboembolism: the eight american college of chest physicians evidence-based clinical practice guidelines. Chest 2008;133;381S-453S.

17. Kearon C, Kahn SR, Agnelli G, Goldhaber S, Raskob GE, Comerota AJ. Antithrombotic therapy for venous thromboembolic disease* :american college of chest physicians evidence-based clinical practice guidelines (8th edition). Chest 2008;133; 454S-545S

18. Hirsh J, Bauer KA, Donati MB, Gould M, Samama MM, Weitz JI. Parenteral anticoagulants* :american college of chest physicians evidence-based clinical practice guidelines (8th edition). Chest 2008;133;141S-159S

19. Peterson D, Harward S, Lawson J.H. Anticoagulation strategies for venous thromboembolism. Perspect Vasc Surg Endovasc Ther 2009; 21;125.

20. Schulman S, Beyth RJ, Kearon C, Levine $\mathrm{MN}$. Hemorrhagic complications of anticoagulant and thrombolytic treatment :american college of chest physicians evidence-based clinical practice guidelines (8th edition). Chest 2008;133;257S-298S

21. Prandoni $\mathrm{P}$, Carnovali M, Marchiori A, et al. Subcutaneous adjusted dose unfractionated heparin vs fixed-dose low-molecular-weight heparin in the initial treatment of venous thromboembolism. Arch Intern Med 2004;164:1077-83.

22. Kearon C, Ginsberg JS, Julian JA, et al. Comparison of fixed-dose weight-adjusted unfractionated heparin and low-molecularweight heparin for acute treatment of venous thromboembolism.JAMA 2006;296:935- 42.

23. Kleber FX, Witt C, MD, Vogel G, Koppenhagen K, Schomaker U, Flosbach 
CW. Randomized comparison of enoxaparin with unfractionated heparin for the prevention of venous thromboembolism in medical patients with heart failure or severe respiratory disease. Am Heart $J$ 2003;145:614-21.

24. Kanaan AO, Silva MA, Donovan JL, Roy T, AI-Homsi S. Meta-Analysis of venous thromboembolism prophylaxis in medically ill patients.Clin Therapeutics2007;29, (11): 2395- 2405

25. Nutescu EA, Spinler SA, Wittkowsky A, Dager WE. Low-molecularweight heparins in renal impairment and obesity: available evidence and clinical practice recommendations across medical and surgical settings. Ann Pharmacother 2009;43:1064-83.

26. Levey SA, Coresh J, Balk E, et al. National Kidney Foundation practice guidelines for chronic kidney disease: evaluation, classification, and stratification. Ann Intern Med 2003;139:137-47.

27. Metzger NL, Chesson MM. Subcutaneous Unfractionated Heparin for Treatment of Venous Thromboembolism in End-Stage Renal Disease. Ann Pharmacother 2010;44:2023-7.

28. Doyle DJ, Turpie AGG, Hirsh J, Best C, Kinch D, Levine MN, Gent M. Adjusted subcutaneous heparin or continuous intravenous heparin in patients with acute deep vein thrombosis: a randomized trial. Annals of Int Med 1987;107:441-445

29. Bentley PG, Kakkar VV, Scully MF, MacGregor IR, Webb P, Chan P, Jones N. An objective study of alternative methods of heparin administration.Thrombosis Research 1980;18;177-187.

30. Andersson G, Fagrell B, Holmgren K, Johnsson H, Ljungberg B, Nilsson E, Wilhelmsson S, ZetterquistS.Subcutaneous
Administration of heparin: a randomized comparison with intravenous administration of heparin to patients with deep-vein thrombosis. Thrombosis Research 1982;27;631-639

31. Robinson AM, McLean KA, Greaves M, Channer KS. Subcutaneous versus intravenous administration of heparin in the treatment of deep vein thrombosis; which do patients prefer? a randomized cross-over study. Postgrad Med J 1993;69:115 - 116

32. Hommes DW, Bura A, Mazzolai L, Buller HR, ten Cate JW. Subcutaneous heparin compared with continuous intravenous heparin administration in the initial treatment of deep vein thrombosis. Ann Intern Med 1992;116:279-84.

33. Suharti C. DasarDasarHemostasis.Dalam :Aru W Sundarudkk. (editor) Buku Ajar IlmuPenyakitDalam.Edisikeempat. Jakarta. PusatPenerbitanDepartemenIlmuPenyakitDal am. Edisikeempat. Jakarta. PusatPenerbitanDepartemenIlmuPenyakitDal am FKUI.2006.

34. Oesman F, Setiabudy RD. FisiologiHemostasisdanFibrinolisis.

Dalam :Rahajuningsih D Setiabudy (editor). HemostasisdanTrombosis. Edisiketiga. Jakarta: BalaiPenerbit FKUI; 2007. hal.1-15

35. Riddle JP, Aouizerat BE, Miaskowski CM, Lillicrap DP. Theories of blood coagulation. Journal of Pediatric Oncology Nursing 2007; 24:123-31

36. Barbui T, Carobbio A, Rambaldi A, Finazzi G. Perspectives on thrombosis in essential thrombocythemia and polycythemia vera: is leukocytosis a causative factor? Blood 2009; 114:759.

37. Visentin GP, Liu CY. Drug-induced thrombocytopenia. Hematol Oncol Clin North Am. Aug 2007;21(4):685-96, vi. 